\title{
New Exact Travelling Wave Solutions for Fractional Differential Equations in a Shallow Water Waves
}

\author{
Adem Cevikel ${ }^{1}$ and Esin Aksoy ${ }^{2}$ \\ ${ }^{1}$ Yildiz Technical Univ. \\ ${ }^{2}$ Yildiz Technical University
}

December 3, 2021

\begin{abstract}
In this article, the modified simple equation method is proposed to solve nonlinear space-time fractional differential equations. This method is applied to solve space-time fractional modified Benjamin-Bona-Mahony (mBBM) equation, the space-time fractional generalized reaction duffing model and the space-time fractional potential Kadomtsev-Petviashvili (pKP) equation. The solutions found are hyperbolic and trigonometric function solutions. Some of these solutions are new solutions that are not available in the literature.
\end{abstract}

\section{Hosted file}

MMAS.pdf available at https://authorea.com/users/449404/articles/547926-new-exacttravelling-wave-solutions-for-fractional-differential-equations-in-a-shallow-water-waves 